\title{
Dual FGF-2 and Intergrin $\alpha 5 \beta 1$ Signaling Mediate GRAF-Induced RhoA Inactivation in a Model of Breast Cancer Dormancy
}

\author{
Judith Barrios • Robert Wieder
}

Received: 5 August 2008 / Accepted: 14 January 2009/Published online: 18 March 2009

(C) The Author(s) 2009. This article is published with open access at Springerlink.com

\begin{abstract}
Interactions with the bone marrow stroma regulate dormancy and survival of breast cancer micrometastases. In an in vitro model of dormancy in the bone marrow, we previously demonstrated that estrogen-dependent breast cancer cells are partially re-differentiated by FGF-2, reexpress integrin $\alpha 5 \beta 1$ lost with malignant transformation and acquire an activated PI3K/Akt pathway. Ligation of integrin $\alpha 5 \beta 1$ by fibronectin and activation of the PI3K pathway both contribute to survival of these dormant cells. Here, we investigated mechanisms responsible for the dormant phenotype. Experiments demonstrate that integrin $\alpha 5 \beta 1$ controls de novo cytoskeletal rearrangements, cell spreading, focal adhesion kinase rearrangement to the cell perimeter and recruitment of a RhoA GAP known as GRAF. This results in the inactivation of RhoA, an effect which is necessary for the stabilization of cortical actin. Experiments also demonstrate that activation of the PI3K pathway by FGF-2 is independent of integrin $\alpha 5 \beta 1$ and is also required for cortical actin reorganization, GRAF membrane relocalization and RhoA inactivation. These data suggest that GRAF-mediated RhoA inactivation and consequent phenotypic changes of dormancy depend on dual signaling by FGF-2-initiated PI3K activation and through ligation of integrin $\alpha 5 \beta 1$ by fibronectin.
\end{abstract}

Keywords Breast cancer - Dormancy · Fibronectin - GRAF . Integrin $\alpha 5 \beta 1 \cdot$ Micrometastases · PI3 kinase · Rho GTPases

\footnotetext{
J. Barrios $\cdot$ R. Wieder $(\bowtie)$

Department of Medicine, UMDNJ-New Jersey

Medical School-University Hospital Cancer Center,

185 South Orange Avenue, CCH1216,

Newark, NJ 07103, USA

e-mail: wiederro@umdnj.edu
}

\section{Introduction}

Breast cancer cells form micrometastases to the bone marrow in about a third of patients with localized disease [1]. These cells become dormant in the bone marrow microenvironment and survive chemotherapy administered with the specific intent of eliminating them [2]. Very little is known about mechanisms that keep these cells in a dormant state. Direct data from individual breast cancer cells, outnumbered more than $10^{8}$-fold by hematopoietic progenitors, is not available. One of the limited options in obtaining molecular data defining the behavior of these cells is by development of models, initially with a limited number of key components that define the in vivo system. Such models can be expanded subsequently to include additional key components in order to determine their effects on the model and validate the data obtained.

Towards understanding basic elements of dormancy, we developed an in vitro model incorporating three key elements affecting breast cancer cell dormancy in the bone marrow microenvironment [3]. The components of our system consist of estrogen-dependent human breast cancer cell lines MCF-7 and T-47D, fibronectin and basic fibroblast growth factor (FGF-2) $10 \mathrm{ng} / \mathrm{ml}$. Estrogen-dependent breast cancer cell lines model estrogen-dependent human tumors, which are likely to remain dormant for extended periods and are least likely to have distant metastatic recurrences [4-6]. In the clinical setting, recurrent estrogen receptor positive cells continue to be estrogen sensitive and susceptible to hormonal blockade [7, 8].

The second element of our system is fibronectin, a structural protein of the bone marrow microenvironment in physical contact with the dormant cells. Fibronectin is found throughout the bone marrow and particularly in the endosteum where homing hematopoietic stem cells have a 
high affinity [9]. Fibronectin is produced in high amounts with a characteristic cellular matrix formation in an extensive network [10] by two types of bone marrow stromal cells, the subendosteal reticulocytes and osteoblasts [11]. Both have functional roles in hematopoiesis, with the latter inducing low proliferation and high maintenance of early haemopoietic progenitors, while reticulocytes promote proliferation and differentiation in an in vitro co-culture model [11]. Evidence suggests that metastatic breast cancer cells usurp the hematopoietic niche and respond to signals from the stromal elements [12]. Fibronectin is upregulated in this pre-metastatic niche primed to receive metastatic cancer cells [12]. In an in vitro co-culture system, tumor cells binding to bone marrow stromal cells exclusively depended on the fibronectin receptor integrin $\alpha 5 \beta 1$ [10].

The third element of our model is basic fibroblast growth factor (FGF-2). FGF-2 is a morphogenic differentiation factor in mammary epithelial cells [13]. It inhibits the proliferation of estrogen-dependent breast cancer cells [14] and promotes their partial re-differentiation [15]. This includes a diminished malignant potential in vitro, including decreased motility and invasion $[15,16]$ and anchorage independent growth [17] and decreased tumor growth in murine xenografts [16]. Breast cancer cells transfected with FGF-2 also form branching duct-like stuctures in Matrigel [15]. FGF-2 is synthesized and exported by the stromal cells $[18,19]$ and deposited in high concentrations in the bone marrow microenvironment [18, 20-22].

In our model, breast cancer cells are incubated on fibronectin-coated tissue culture plates in the presence of FGF-2 $10 \mathrm{ng} / \mathrm{ml}$ at clonogenic density, where their primary interaction is with the substratum and not with each other [3]. In the model, cells form dormant clones of 2-12 cells over a 6-day period in contrast to cells incubated without FGF-2, which form proliferating clones of greater than 30 cells. The dormant cells become growth arrested, re-express integrins $\alpha 2, \alpha 5, \beta 1 \beta 3$ and $\beta 4$, lost with transformation [23-25], and adopt a characteristic morphogenic trait of large size and a highly spread out conformation with large cytoplasm to nucleus ratios [3]. They undergo sustained activation of the phosphoinositol 3-kinase (PI3K) pathway [3] and extracellular receptor kinase (ERK) pathway [26], which, along with ligation of integrin $\alpha 5 \beta 1$, contribute to their survival [3].

We wanted to determine the steady-state molecular events that sustained dormancy in these cells. Specifically, we wanted to discern whether the signaling mediating these effects was initiated by FGF-2 directly or through integrin $\alpha 5 \beta 1$, which is induced by FGF-2 incubation as the cells reach a dormant steady-state. The phenotypic appearance of the estrogen-dependent cells in the dormancy model was reminiscent of that of FGF-2-transfected MDA-MB-231 cells. MDA-MB-231 cancer cells enforced to express FGF-
2 acquired a spread appearance, cortical redistribution of fibrillar actin (F-actin), omnidirectional focal complex activation [27], and decreased motility, invasiveness and in vivo tumorigenicity [16]. We investigated the characteristics of the dormant cells in the context of our prior observations to determine if the partial re-differentiation of the dormant cells was due to potential inhibitory effects on the activation state of small GTPases, specifically RhoA, implicated in actin polymerization and cancer progression [28]. Our observations suggest that inhibition of RhoA, which trends to higher expression with tumor grade and nodal metastasis in breast cancer [29], may play a functional role in the partial re-differentiation of breast cancer dormancy in the bone marrow microenvironment.

\section{Materials and Methods}

\section{Cells and Cell Culture}

MCF-7 cell were obtained from ATCC (American Type Culture Collection) and cultured in Dulbecco's modified Eagle medium supplemented with $10 \%$ fetal calf serum (DMEM $/ 10 \%$ FCS) (standard medium) as before [3]. MCF$10 \mathrm{~A}$ cells (ATCC) were cultured in MCF-10 medium in standard tissue culture plates, as before [30]. Cells were incubated at clonogenic densities of 50,000-75,000 cells per $10 \mathrm{~cm}$ fibronectin pre-coated plates purchased from BIOCOAT, BD Biosciences, or 15,000 cells per well in 6 well plates (day -1) and supplemented with $10 \mathrm{ng} / \mathrm{ml}$ basic FGF (FGF-2) (Invitrogen) the following day (day 0). DMEM $/ 10 \%$ FCS with FGF-2 $10 \mathrm{ng} / \mathrm{ml}$ was replenished on day 3 , along with addition of inhibitors and antibodies in specific experiments (LY $29400225 \mu \mathrm{M}$ (Calbiochem), integrin $\alpha 5 \beta 1$ or $\alpha 2 \beta 1$ blocking antibodies $2 \mu \mathrm{g} / \mathrm{ml}$ (Chemicon), integrin blocking peptides to fibronectin (GRGDSP (P1)), to collagen (CQDSETRTFY (P3), and a non-binding control (GRGESP (P2)) (American Peptide Co., Sunnyvale, CA) $100 \mathrm{nM}$ in $10 \%$ DMEM), as previously described [3]. For all experiments except transfections, cells were harvested and analyzed on day 6 .

\section{Indirect Immunofluorescence and Phallacidin Staining}

Cells were cultured on FN coated $22 \mathrm{~mm}$ slides (BD Biosciences) which were situated in 6 well tissue culture plates, and inhibitors and blocking agents were added on day 3, as above. Slides were removed on day 6 and cells were fixed in $3.7 \%$ formaldehyde in PBS for $10 \mathrm{~min}$. For phalloidin staining, slides were blocked in $1 \%$ bovine serum albumin (BSA) for $30 \mathrm{~min}$ and incubated in BODIPY-Phallacidin (green) or rhodamine phalloidin (red) (Molecular Probes) at room temperature for $20 \mathrm{~min}$. For 
indirect immunofluorecence staining, cells were blocked in $5 \%$ BSA for one $\mathrm{h}$, incubated with primary antibodies diluted in PBS $0.1 \%$ TRITON X-100, with overnight incubation at $4{ }^{\circ} \mathrm{C}$ (Santa Cruz Biotechnology). Coverslips were washed and incubated with ALEXA FLOUR conjugated antibodies (Molecular Probes) and mounted on glass slides using Prolong Gold with Dapi (Molecular Probes). Cells were viewed and photographed using a ZEISS Axiovert $200 \mathrm{M}$ microscope fitted with an ApoTome Imaging system. Phalloidin staining was quantitated on 400 x magnification. RhoA, GRAF and p190 Rho GAP indirect immunofluorescence slides were photographed at 630 x. Phospho-FAK Y397 quantitation was performed on an Olympus BX20 fluorescence microscope and an Olympus MagnaFire digital photographic system at 1,000x magnification.

Immunoprecipitation, Rho GTP Assays and Western Blots

For Immunoprecipitation, cells were incubated at clonogenic density on $10 \mathrm{~cm}$ fibronectin-coated plates, and cultured as above, harvested and lysed on day 6 in 1X modified RIPA buffer (Millipore) (approximately 2.5 million cells or $1 \mathrm{mg}$ total protein). Pre-cleared lysates were subjected to immunoprecipitation using 10ug FAK antibody-conjugated agarose (Millipore) overnight at $4^{\circ} \mathrm{C}$. Beads were washed in modified RIPA lysis buffer and collected by centrifugation at $10,000 \mathrm{X}$ $\mathrm{g}$, at $4^{\circ} \mathrm{C}$. The beads were boiled in $1 \mathrm{X}$ Lamelli buffer (BIORAD) for $5 \mathrm{~min}$ and subjected to SDS PAGE for western blot analysis.

For Rho GTP assays, equal numbers of cells were used because the dormant cells exhibited a larger cytoplasm to nucleus ratio and contained approximately $20 \%$ more protein than the growing cells (approximately 2.5 million cells, or $1 \mathrm{mg}$ protein). Cells were harvested and lysed using 1X Mg Lysis buffer (Millipore). Rho GTP was immunoprecipitated using rhotekin RBD-agarose slurry (Millipore), which exclusively binds RhoGTP, according to the manufacturer's instructions. Beads were washed, resuspended in 1X Laemmli buffer (Biorad) and subjected to SDS PAGE and immunoblotting for RhoA (Santa Cruz Biotechnology). For western blots, samples were transferred to PVDF membranes, blocked in 2\% BSA 1X TBS$\mathrm{T}$, followed by addition of primary antibodies (SantaCruz Biotechnology and Millipore) and detected via chemiluminescence (Amersham).

\section{Transfection and RhoA Constructs}

RhoA DNA constructs, (kind gifts of Ian Whitehead), were grown as described [31]. Briefly, cDNAs encoding human wild-type RhoA, fused to an $\mathrm{NH}_{2}$-terminal hemagluttinin (HA)-epitope tag were generated and cloned into pAX142.
An identical mutant panel was generated for each isoform: RhoA-19N (dominant-inhibitory), RhoAWT (wild type), and RhoA-63L (constitutively active) [32]. DNA was isolated from bacterial cultures using Highspeed Plasmid MAXI Kit, (Qiagen) according to the manufacturer's instructions. RhoA constructs were transfected using Fugene6 transfection reagent (Roche) according to the manufacturer's instructions into MCF-7 cells cultured at clonogenic density on FN coated coverslips. Rho constructs were co-transfected with pmaxGFP DNA (AMAXA) at previously optimized concentrations for maximum transfection efficiency at ratios of 10:1 or $3.0 \mu \mathrm{g}$ RhoA constructs $/ 0.3 \mu \mathrm{g}$ GFP vector DNA. Medium was replenished at $12 \mathrm{~h}$, and FGF-2 $10 \mathrm{ng} / \mathrm{ml}$ was added on day 2 after transfection. Cells were stained with rhodamine phalloidin on day 4 following transfection, as described above. Cells were counted as having cortical actin rearrangement when $>50 \%$ of the cell's periphery was subtended by cortical actin. GFP positive cells in dormant clones (consisting of $<12$ cells) or in growing clones ( $>30$ cells) were used for quantitation. Triplicate cover slips were independently transfected in two separate experiments. Means and standard deviations for data collected from green fluorescent cells on the three slides were calculated in each experiment and the significance of differences between different vector transfections were determined using Student's $t$ test.

\section{Cell Fractionation}

The Qiagen Qproteome Cell Compartment fractionation kit (Qiagen) was used to isolate plasma membranes and cytoplasmic fractions from cells in dormant or growing clones according to the manufacturer's protocol. Briefly, equal numbers of cells from dormant (+FGF-2) or growing (-FGF-2) clones cultured on FN-coated plates were subjected to sequential centrifugation during which soluble fractions containing plasma membrane and cytosolic fractions were extracted. Fractions were subjected to SDS PAGE and immunoblotted with anti-GRAF goat polyclonal antibody (Santa Cruz Biotechnology) and anti-BAX antibody as a localization control.

\section{Results}

Integrin $\alpha 5 \beta 1$ Binding is Necessary for Cortical Actin Redistribution in Dormant Cells

Using a three component system consisting of cells, FGF-2 $10 \mathrm{ng} / \mathrm{ml}$ and fibronectin, we previously demonstrated that estrogen sensitive human breast cancer cells become quiescent, re-express integrins lost with malignant de-differentiation and acquire a spread appearance with increased cytoplasm to 
nucleus ratios [3]. To determine if the appearance of the cells in the dormant clones was due to cortically rearranged Factin, a characteristic of non-transformed mammary epithelial cells [33], we stained them with phallacidin. Figures $1 \mathrm{a}$ and $\mathrm{b}$ demonstrate that $74.1+7.8 \%$ of these very large, quiescent cells have parallel bundles of cortical actin as compared with $33.0+11.5 \%$ of cells in growing colonies. This difference is significant at $p<0.01$ (Student's $\mathrm{t}$ test). Analogously, MCF$10 \mathrm{~A}$ non-transformed, immortalized mammary epithelial cells incubated on fibronectin also have a cortical actin distribution. To test the hypothesis that the re-differentiated state depends on outside-in signaling through re-expressed integrin $\alpha 5 \beta 1$, we incubated the cells growing on fibronectin with blocking antibodies to this integrin. Figure 2 a demonstrates that cortical rearrangement of $\mathrm{F}$-actin requires binding of integrin $\alpha 5 \beta 1$ by fibronectin, while blocking antibody to integrin $\alpha 2 \beta 1$, also upregulated in these dormant cells [3], has no effect and acts as a negative control. The increase in the percent cells with cortical actin from $28.6+$ $0.9 \%$ of growing cells to $67.9+6.6 \%$ of dormant cells and the decrease back to $21.6+8.5 \%$ due to blocking of integrin $\alpha 5 \beta 1$ binding are statistically significant $(p<0.005$,
Fig. 2 Cortical actin stabilization in dormant breast cancer cells is integrin $\alpha 5 \beta 1$-dependent. MCF-7 cells were incubated with or without FGF-2 $10 \mathrm{ng} / \mathrm{ml}$ on fibronectin-coated cover slips at clonogenic density. Blocking antibodies to integrin $\alpha 5 \beta 1$ and integrin $\alpha 2 \beta 12 \mu \mathrm{g} / \mathrm{ml}$ were added on day 3. Cells were stained with rhodamine phalloidin (red actin staining) and DAPI (blue nuclear staining) and photographed at $400 \mathrm{x}$ magnification. A $20 \mu \mathrm{M}$ size bar is included in all photographs. a Blocking antibody to integrin $\alpha 5 \beta 1$, the fibronectin receptor upregulated in dormant MCF-7 cells, reversed the cortical redistribution of fibrillar actin, the increased nuclear size and the increased cytoplasm to nucleus ratios in dormant cells. Blocking antibody to integrin $\alpha 2 \beta 1$, the upregulated collagen receptor, had no effect. b Quantitative representation of the percentage of manually counted cells with cortical actin on triplicate slides from a duplicate experiment. c Quantitative representation of the maximal longitudinal axis of the nuclei and $\mathbf{d}$ Quantitative representation of the square of the ratio of the maximal cytoplasm long axis to that of the maximal nuclear long axis. Error bars are + standard deviations. ${ }^{*} p<0.005,{ }^{* *} p<0.001$ (Student's t test)

$p<0.001$, respectively, Fig. 2 b). Antibody to integrin $\alpha 2 \beta 1$ had no effect with $66.0+13.2 \%$ of the cells having cortical actin $(p>0.05)$. Other characteristics of these dormant cells, including increased nuclear size (Fig. 2c) and increased

\section{a}

\section{FGF-2}

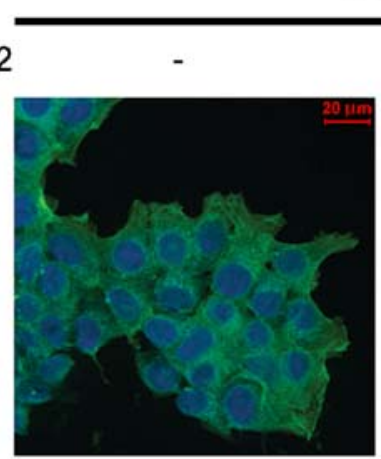

MCF-7
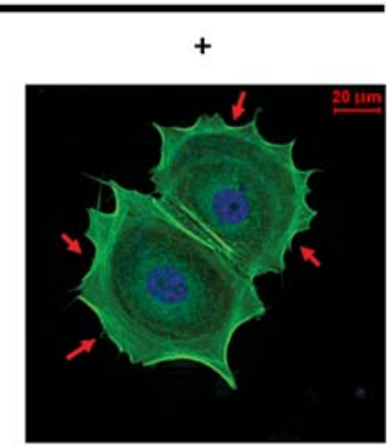

*

b

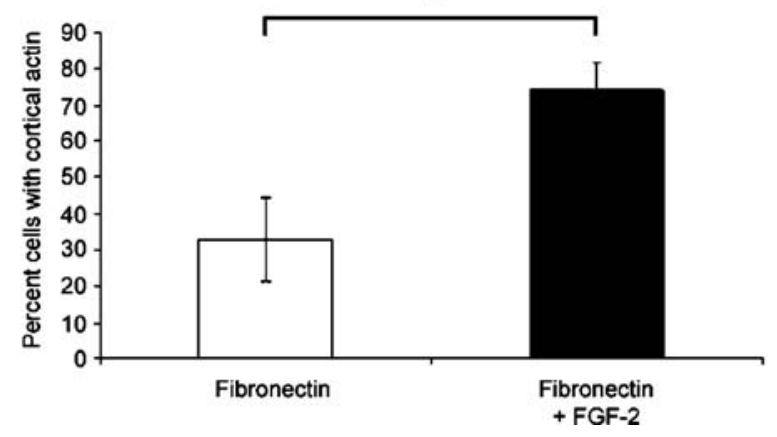

MCF-10A

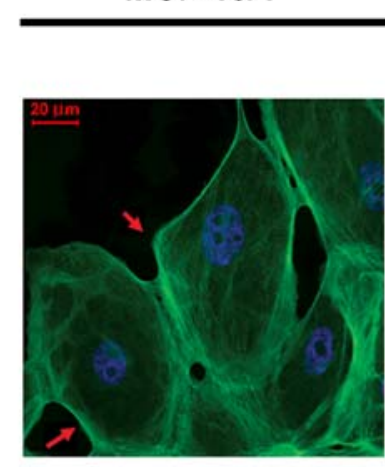

Fig. 1 Cortical actin stabilization in dormant breast cancer cells. a MCF-7 cells incubated with or without FGF-2 $10 \mathrm{ng} / \mathrm{ml}$ on fibronectin-coated cover slips for 6 days at clonogenic density were stained with BODIPY-Phallacidin (green actin staining) and DAPI (blue nuclear staining) and photographed at $400 \mathrm{x}$ magnification (see Materials and Methods). A $20 \mu \mathrm{M}$ size bar is included in all fluorescence photographs in all figures. MCF-10A cells were incubated on fibronectin-coated slides and stained in a similar manner as controls and demonstrate morphological similarity with dormant MCF-7 cells. Arrows indicate prominent places of cortical actin redistribution around the perimeter of the cytoplasm. b The percentages of cells with cortical actin distribution of $>50 \%$ of the perimeter were manually counted in approximately 100 cells and graphed. Experiments were done in triplicate slides. Error bars are + standard deviations. ${ }^{*} p<0.01$ (Student's t test) 
a

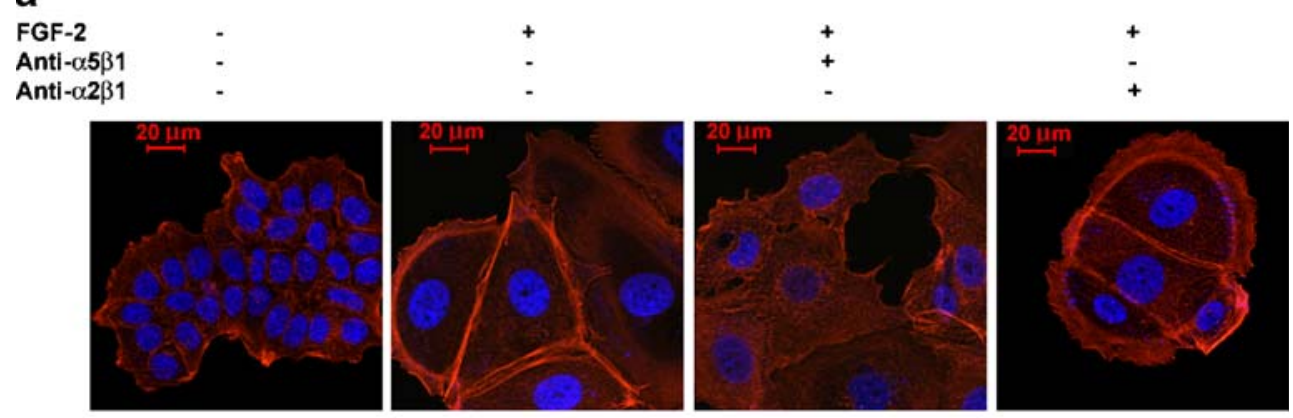

b

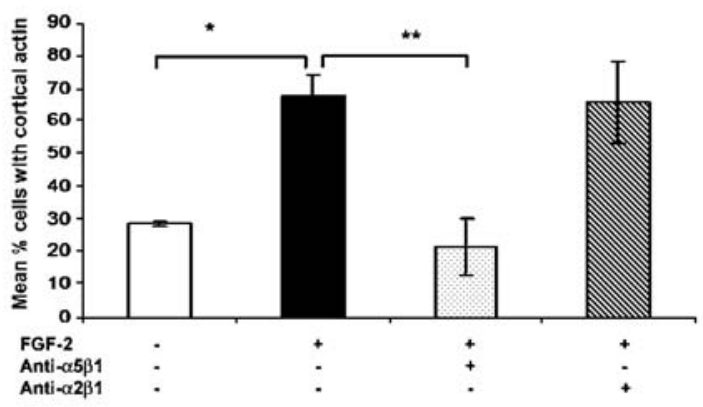

C

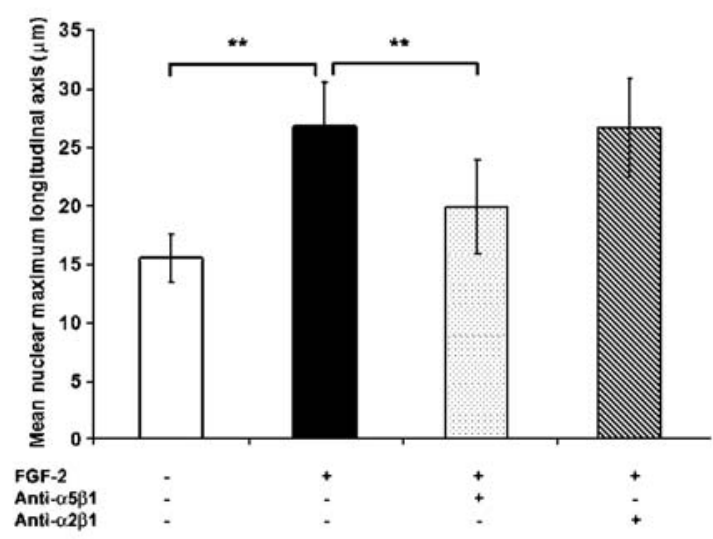

d

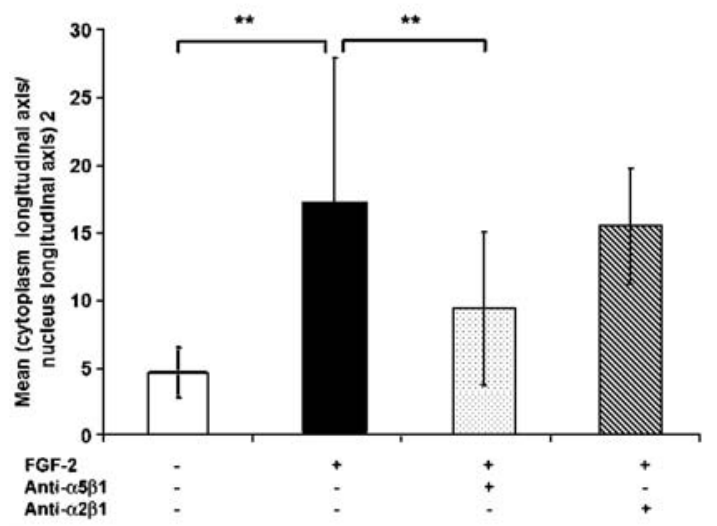

cytoplasm to nucleus ratios (Fig. 2d) were also partially reversed by blocking antibody to integrin $\alpha 5 \beta 1$. The mean longitudinal nuclear axis increased from $15.4+2.0 \mu \mathrm{m}$ in growing cells to $26.7+3.7 \mu \mathrm{m}$ in dormant cells $(p<0.001)$ and was reversed to $19.8+4.0$ with blocking antibody to integrin $\alpha 5 \beta 1 \quad(p<0.001)$. Blocking antibody to integrin $\alpha 2 \beta 1$ did not have an affect. Similarly, the mean square of the cytoplasm to nucleus ratios increased from $4.6+1.9$ in growing cells to $17.2+10.7$ in dormant cells and was reversed to $9.48+5.6$ with blocking antibody to integrin $\alpha 5 \beta 1 \quad(p<0.001)$. Blocking antibody to integrin $\alpha 2 \beta 1$ did not have an affect on this characteristic either. 
Inactivation of Rhoa is Necessary but not Sufficient for Cortical Actin Redistribution in Dormant Cells

We measured the activation of Rho A responsible for modulating actin polymerization dynamics. Figure $3 \mathrm{a}$ demonstrates that Rho A GTP levels were significantly diminished in the dormant cells as compared to those in growing cells. The effect depended on specific integrin $\alpha 5 \beta 1$ binding by fibronectin, as blocking antibody to integrin $\alpha 5 \beta 1$ restored RhoA activation while blocking antibody to integrin $\alpha 2 \beta 1$ had only a partial effect. The Rho A GTP-loaded state and its dependence on integrin $\alpha 5 \beta 1$ activation is reflected in membrane localization of Rho A in growing cells on fibronectin, re-internalization in dormant cells and relocalization to the membrane by blocking antibodies to integrin $\alpha 5 \beta 1$ in immunofluorescence assays (Fig. 3b).

To determine if the actin reorganization was dependent on RhoA inactivation, we transfected cells on fibronectin- coated cover slips with wild type, constitutively active and dominant negative RhoA expression vectors and quantitated the percentage of transfected cells with cortical actin by indirect immunofluorescence. Cells were transiently cotransfected with a GFP vector and ten-fold excesses of the various RhoA expression vectors. Actin localization in green fluorescent cells was determined by rhodamine red phalloidin staining. Figure $4 \mathrm{a}$ demonstrates prototypical membrane localization of actin in GFP-only- and dominant negative RhoA 19N-transfected dormant cells and significantly diminished peripheral actin localization in wild typeor constitutively active Rho 63L-transfected dormant cells. In the latter transfectants, the appearance of stress fibers became evident. The data, graphed in Fig. 4b, confirms once again the increase in the percentage of cells with cortically rearranged actin around more than $50 \%$ of the periphery from $9+0.7 \%$ of the growing cells to $80+2 \%$ of the dormant cells $(p<0.01)$. No significant differences were noted between mock transfected and GFP only-transfected

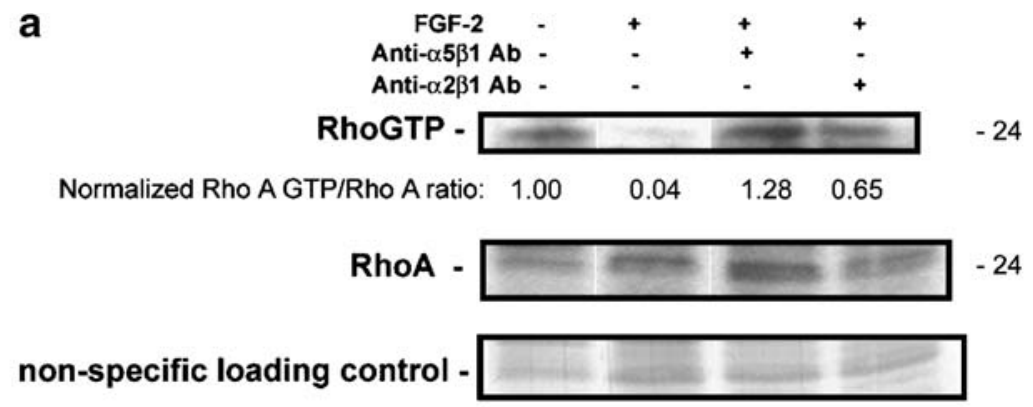

b

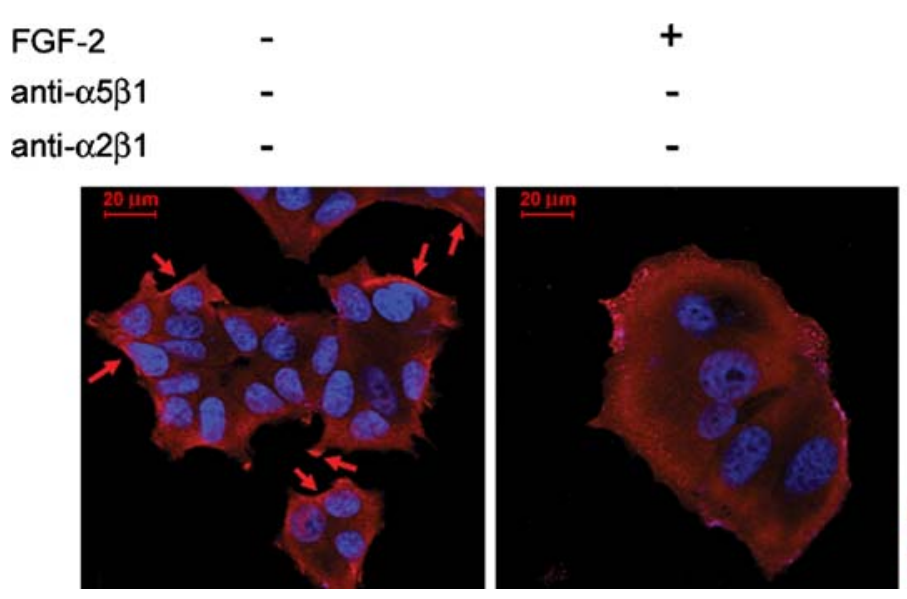

Fig. 3 Downregulation of RhoA GTP-loading in dormant MCF-7 breast cancer cells is integrin $\alpha 5 \beta 1$-dependent. a Cells were incubated on 10-12 fibronectin-coated $10 \mathrm{~cm}$ plates per condition and cultured as described. On day 6, equal cell numbers were lysed, incubated with Rhotekin-conjugated agarose, precipitated and analyzed by western blot with anti-RhoA antibody. Total lysates were used for RhoA western blot controls and a nonspecific band on the Coomasie-stained membrane was used as a loading control to confirm the increased protein content of dormant cells. RhoA GTP and total Rho bands were quantitated with a densitometer and ratios were normalized to that of

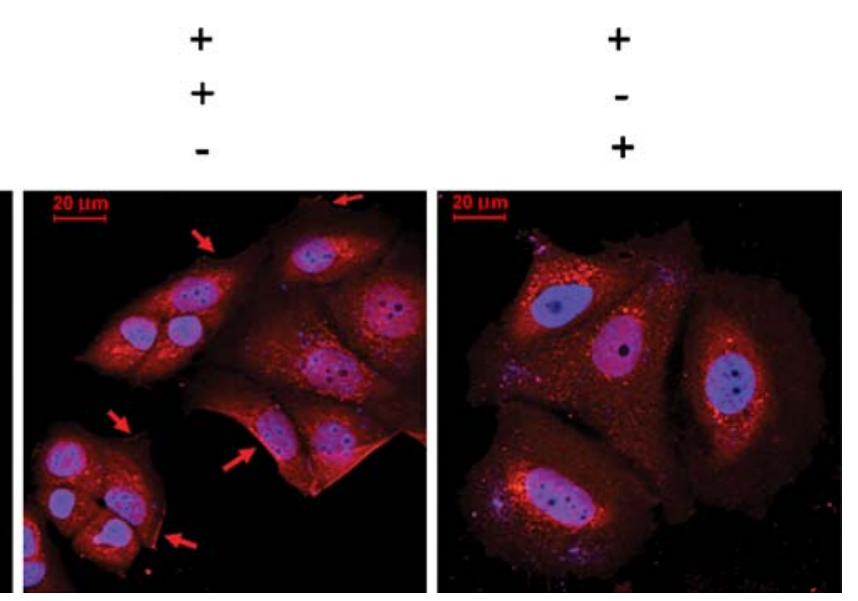

growing cells. The experiment was done three times. b The RhoA GTP-loading data was corroborated by indirect immunofluorescencestaining of cells on fibronectin-coated cover slips with anti-RhoA antibody (red) and photography at $630 \mathrm{x}$ magnification. Growing cells exhibited membrane localization of RhoA (arrows) which disappeared in dormant cells. Blocking antibody to integrin $\alpha 5 \beta 12 \mu \mathrm{g} / \mathrm{ml}$ induced re-localization of RhoA to the membrane, while blocking antibody to integrin $\alpha 2 \beta 12 \mu \mathrm{g} / \mathrm{ml}$ had only a minimal effect. Nuclear DAPI staining is shown in blue 
a

FGF-2

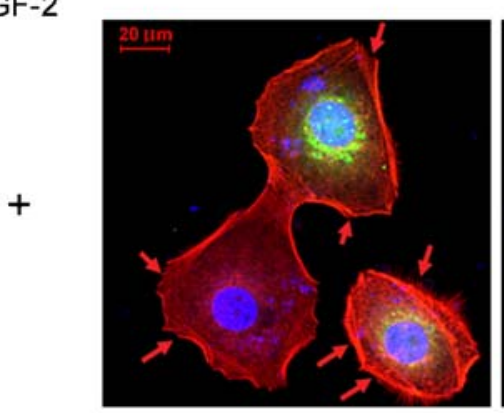

RhoA 19N

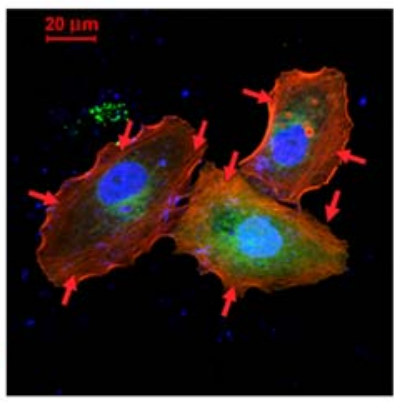

RhoA 63L

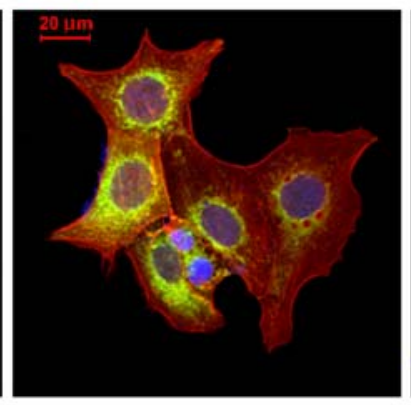

RhoA WT

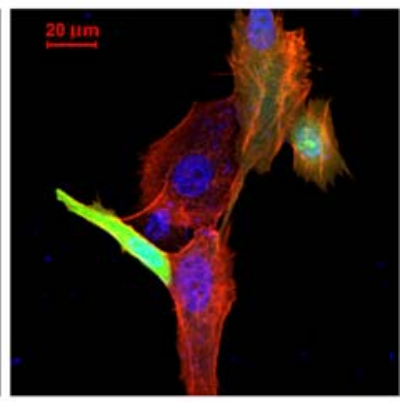

b

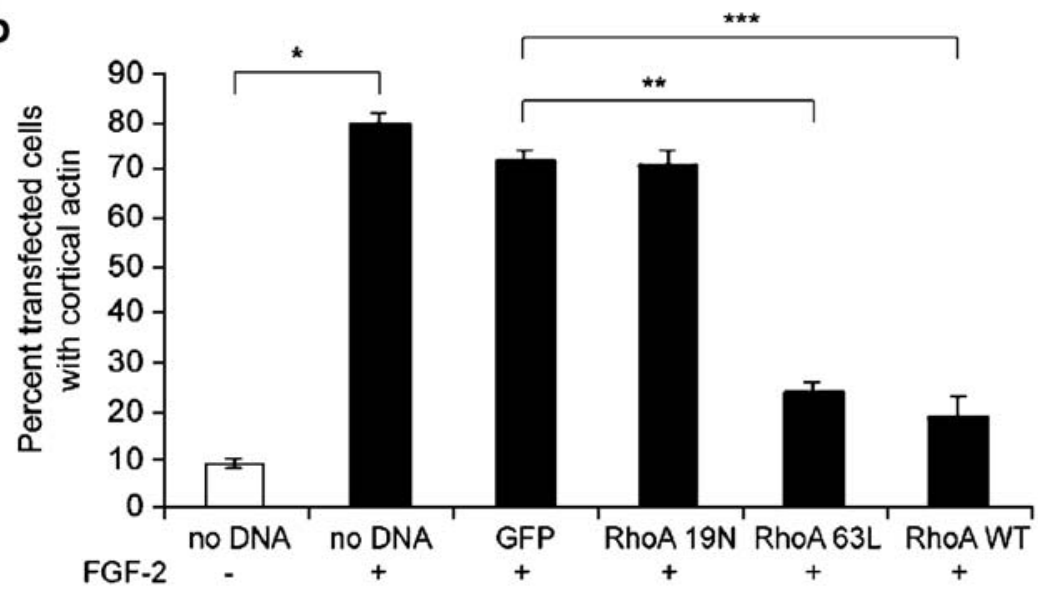

C

FGF-2

GFP only

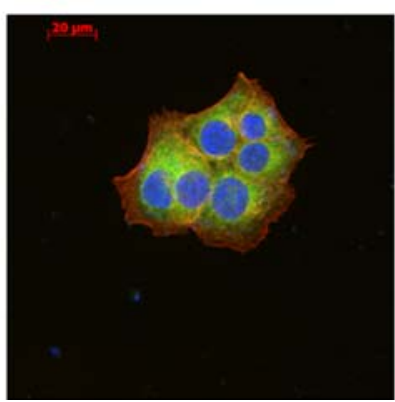

RhoA 19 N

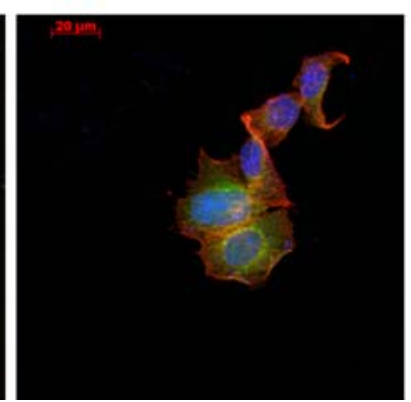

d

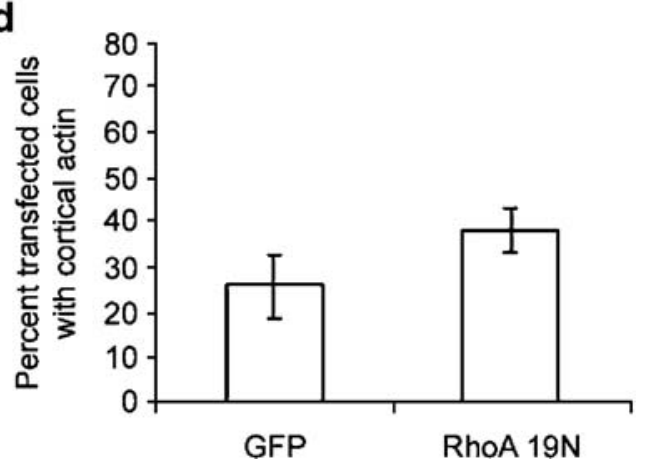

Fig. 4 Downregulation of RhoA GTP-loading is necessary but not sufficient for cortical actin rearrangement in dormant cells. Cells on fibronectin-coated cover slips in medium containing FGF-2 $10 \mathrm{ng} / \mathrm{ml}$ (A. and B.) or lacking FGF-2 (C. and D.) were transiently transfected with 10:1 ratios of the three RhoA vectors and the GFP vector or with the GFP vector alone and stained with rhodamine phalloidin (red) and DAPI (blue nuclear staining). Cortical actin was identified and quantitated in the GFP-transfected green cells only. a Cortical distribution of F-actin was observed in GFP only- and RhoA 19N (dominant negative)-transfected dormant cells (arrows), but was markedly diminished in dormant cells transfected with RhoA63L (constitutively active) or RhoA wild type (RhoAWT). These latter two transfectants also induced the appearance of stress fibers. Cells were photographed at $400 \mathrm{x}$ magnification. b Quantitative assessment of the

dormant cells. Transfection of dormant cells with dominant negative RhoA 19N did not decrease the percentage of cells with cortical actin. However, transfection with constitutively active $63 \mathrm{~L}$ and wild type RhoA decreased the percentage percentage of cells with $>50 \%$ cortical distribution demonstrates a statistically significant increase in cortical actin in dormant cells compared with growing cells $\left({ }^{*} p<0.01\right)$, between GFP- and RhoA63L-transfected dormant cells $(* * p<0.001)$ and between GFPand RhoAWT-transfected dormant cells $(* * * p<0.02)$ (Student's t test). Error bars are + standard deviations. All other differences were not statistically significant. c Transfection of growing cells with dominant negative RhoA $19 \mathrm{~N}$ did not induce either the dormant phenotype or actin rearrangement. Transfection with either constitutively active RhoA63L or wild type RhoA also did not affect cortical actin (not shown). D. Statistical comparison of cell distributions with cortical actin was not affected in growing cells by dominant negative RhoA19N, nor by the other vectors (not shown)

of cells with cortical actin to $24+2(p<0.001)$ and $10+4 \%$, $(p<0.02)$, respectively. These data demonstrate that inactivation of RhoA is necessary to permit the acquisition of the dormant phenotype. To determine if inactivation of RhoA 
was sufficient to induce the state of dormancy, as defined by a spread cellular appearance and cortical actin redistribution, growing cells were transfected with dominant negative RhoA $19 \mathrm{~N}$ vector. Figure $4 \mathrm{c}$ demonstrates that the cells did not acquire the characteristic appearance and did not develop cortically rearranged actin. Figure $4 d$ demonstrates that there was no statistically significant increase in the percentage of cells with cortical actin between GFP only-transfected and RhoA 19N-transfected growing cells, nor did the cells acquire the typically large, spread out appearance of the dormant cells. Transfection with wild type and dominant negative vectors had no effect either, as expected (data not shown). These data demonstrate that the inhibition of RhoA activation is not sufficient to induce the dormant phenotype.

\section{Activation of Focal Adhesion kinase in Dormant Cells is Associated with Membrane Localization of the GTP Activating Protein GRAF}

We investigated whether focal adhesion kinase (FAK) was affected in dormant cells as part of the re-differentiation process. Integrin-mediated cell adhesion activates FAK and results in focal adhesion complex formation, initiation of stress fiber formation and motility [34]. The cellular levels
Fig. 6 Integrin $\alpha 5 \beta 1$-dependent peripherally localized phospho-Y397 FAK in dormant cells is associated with membrane localization of the RhoA GAP GRAF. a Cells incubated on fibronectin-coated tissue culture plates with and without FGF-2 $10 \mathrm{ng} / \mathrm{ml}$ with control or blocking antibodies to integrin $\alpha 5 \beta 1$ and integrin $\alpha 2 \beta 12 \mu \mathrm{g} / \mathrm{ml}$ added on day 3 were harvested on day 6 . Lysates from equal cell numbers were immunoprecipitated with antibody to FAK and stained on western blot with anti-phospho-Y397 FAK antibody, total FAK antibody and GRAF antibody. Bands were quantitated using a densitometer and ratios of phospho-FAK to FAK and GRAF to phospho-FAK were normalized to the bands from dormant cells in the immunoprecipitates. Ratios of phospho-FAK to total FAK and total FAK to control bands were also normalized to dormant cells. b GRAF membrane localization in dormant cells and the corresponding RhoA departure form its membrane localization was demonstrated on immunofluorescence-stained cells on fibronectin-coated cover slips (red) and photography at $630 \mathrm{x}$ magnification. Growing cells exhibited membrane localization of RhoA (arrows) which disappeared in dormant cells, while GRAF membrane localization appeared in dormant cells (arrows). Immunostaining with antibody to p190 Rho GAP was used as a negative control, demonstrating no evident staining in either growing or dormant cells. Nuclear DAPI staining is shown in blue. c Membrane fractionation of growing and dormant cells with and without added blocking antibodies to integrin $\alpha 5 \beta 1$ and integrin $\alpha 2 \beta 12 \mu \mathrm{g} / \mathrm{ml}$ and western blotting of isolates with antibody to GRAF and BAX, used as a cytoplasm-localizing control. Bands were quantitated using a densitometer and ratios of membrane- to cytoplasm-localizing GRAF and BAX were calculated
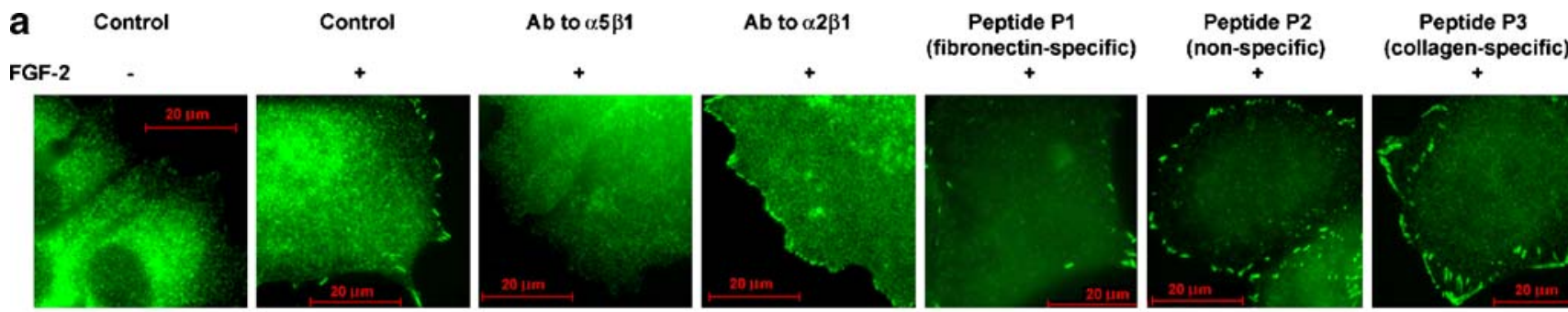

b

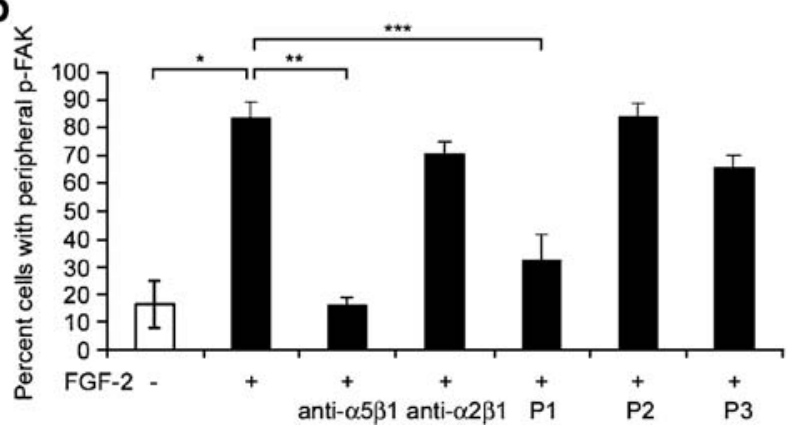

Fig. 5 Peripheral phospho-Y397 FAK localization in dormant cells is integrin $\alpha 5 \beta 1$-dependent. a MCF-7 cells were incubated on fibronectin-coated cover slips with medium containing FGF-2 $10 \mathrm{ng} / \mathrm{ml}$. Blocking antibodies to integrin $\alpha 5 \beta 1$ and integrin $\alpha 2 \beta 12 \mu \mathrm{g} / \mathrm{ml}$ and blocking peptides to fibronectin (P1), to collagen (P3), and a nonbinding control (P2) $100 \mathrm{nM}$ were added on day 3 as described in Materials and Methods. Cells were stained with antibodies to phospho-Y397 FAK on day 6 and photographed at 1,000 x magnification. Localization of phospho-Y397 FAK with dormancy is

reversed by blocking fibronectin binding with blocking antibody to integrin $\alpha 5 \beta 1$ or blocking peptide P1 to fibronectin. b Graphic depiction of induction of peripheral phospho-Y397 FAK in dormant cells $\left({ }^{*} p<0.005\right)$, and reversal of localization by blocking antibody to integrin $\alpha 5 \beta 1(* * p<0.001)$ and blocking peptide to fibronectin P1 $(* * * p<0.01)$ (Student's $t$ test). Error bars are + standard deviations. All other differences were not statistically significant. Data is from one of two duplicate experiments with triplicate slides with approximately 100 cells counted per slide 
a

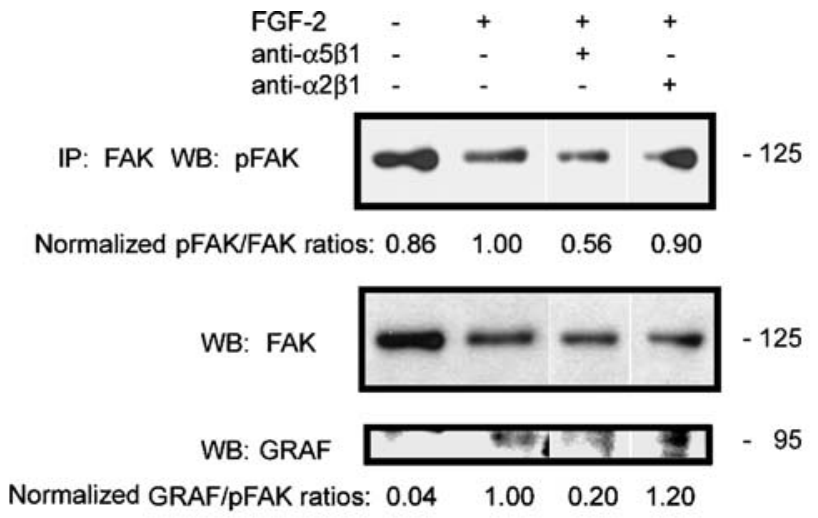

b

FGF-2

Rho A
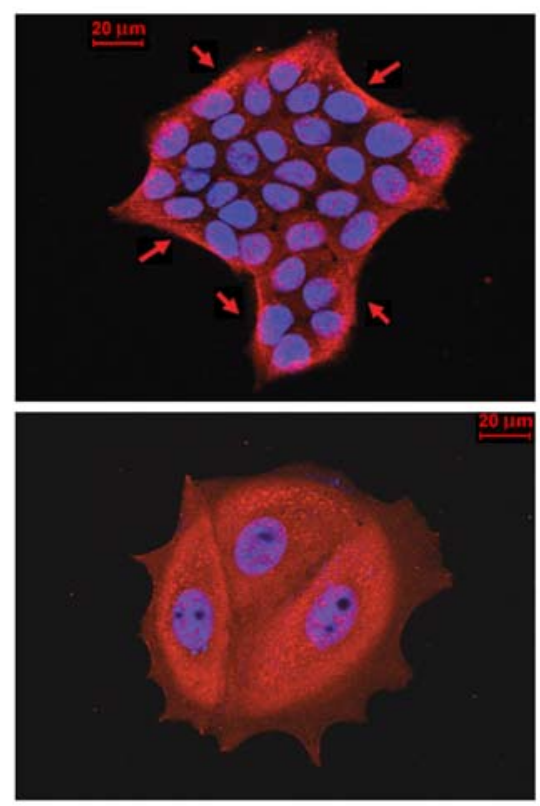

C
GRAF
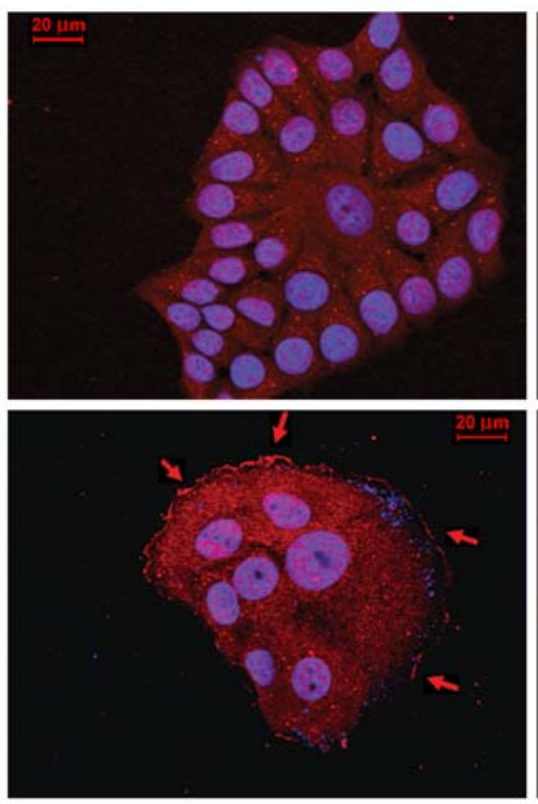

p190 Rho GAP
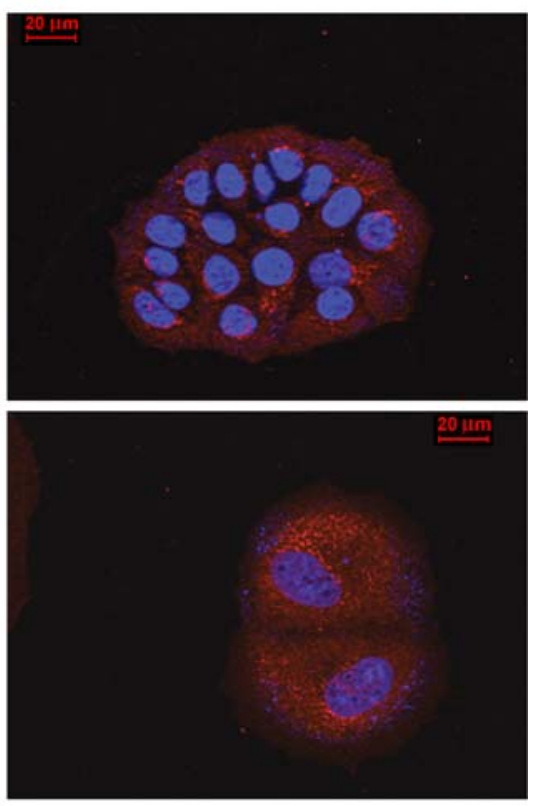
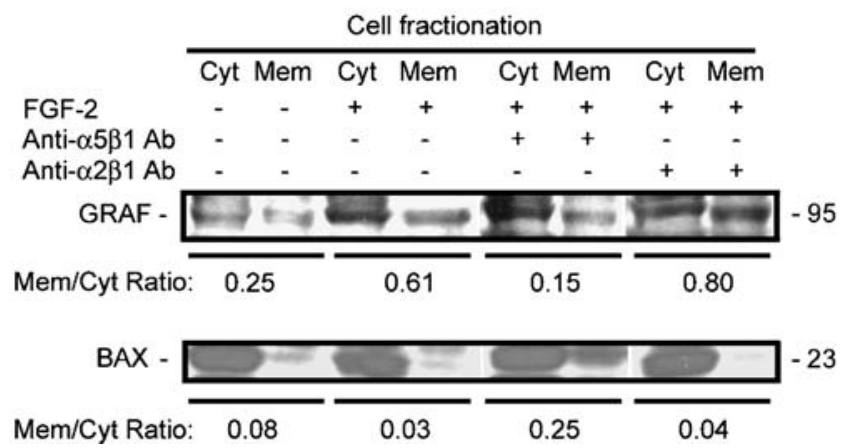

and activation state of FAK are increased in breast cancer progression [35-39]. In this context however, we found that instead of inactivation with dormancy, FAK became membrane localized and activated in the dormant cells. The percentage of cells staining for peripheral, activated Y397 phospho-FAK increased from $16.5+8.6 \%$ of growing cells to $83.1+12.6 \%$ of dormant cells $(p<0.005)$ (Fig. 5). This activation depended on binding of integrin $\alpha 5 \beta 1$, as integrin $\alpha 5 \beta 1$ blocking antibody or fibronectin blocking peptide P1 incubated with dormant cells decreased the percentage of cells with peripherally staining activated FAK to $15.9+2.9 \%$ $(p<0.001)$ and $32.2+9.5 \%(p<0.01)$, respectively. Control blocking antibody to integrin $\alpha 2 \beta 1$, non-binding control peptide P2 or collagen blocking peptide P3 had no effect, with peripheral FAK activation remaining at $70.6+4.5 \%$, $83.6+4.9 \%$ and $65.7+4.7 \%$, respectively, in dormant cells. 
To support these data, we immunoprecipitated FAK from lysates prepared from dormant and growing cells and immunostained western blots with antibodies to phosphoY397 FAK and total FAK. Figure 6a demonstrates that total FAK levels decreased in dormant cells as demonstrated by IP/western blots, while phospho-Y397 FAK levels in the cells slightly increased. The increase in phospho-Y397 was dependent on integrin $\alpha 5 \beta 1$, as blocking antibody decreased the rate of this phosphorylation in the IP/westerns, while blocking antibody to integrin $\alpha 2 \beta 1$ had no effect. The overall increase in phospho-Y397 FAK was small when whole cellular lysates were assayed by IP/western blot in all of the experiments, while the decreases with integrin $\alpha 5 \beta 1$ blocking antibody were consistent. However, the physiologically significant increase in membrane localization of activated FAK was markedly pronounced and significant, as demonstrated by the immunofluorescence staining for phospho-FAK.

To determine a possible mechanism for the inactivation of RhoA in dormant cells, we analyzed the FAK immunoprecipitates for GTPase Regulator Associated with the Focal Adhesion Kinase pp125(FAK) (GRAF), a protein with demonstrated RhoA GAP activity shown to colocalize with activated FAK in focal complexes. Figure 6a suggests that GRAF becomes associated with FAK in dormant cells, an effect exclusively dependent on integrin $\alpha 5 \beta 1$. To confirm this result, we analyzed the cells by immunfluorescence. Figure $6 \mathrm{~b}$ demonstrates that GRAF became membrane localized in the dormant cells in a reciprocal relationship to the loss of RhoA membrane localization. As a control, Fig 6b demonstrates that the RhoA GAP p190 was not affected in dormant cells. To further confirm the activation by membrane localization of GRAF in dormancy, we carried out membrane fractionation experiments. Figure $6 \mathrm{c}$ demonstrates that GRAF was primarily cytoplasm localized in growing cells with a membrane to cytoplasm $(\mathrm{m} / \mathrm{c})$ ratio of 0.25 . In dormant cells, GRAF membrane localization increased to an $\mathrm{m} / \mathrm{c}$ ratio of 0.61 . This effect once again was dependent on integrin $\alpha 5 \beta 1$, as blocking antibody to this integrin decreased the ratio to 0.15 . With blocking antibody to integrin $\alpha 2 \beta 1$ used as a control, the GRAF $\mathrm{m} / \mathrm{c}$ ratio was 0.80 . These data support the hypothesis that the RhoA GAP GRAF becomes activated and membrane localized in dormant cells causing an inactivation of RhoA and that this effect depends on binding of integrin $\alpha 5 \beta 1$.

Activation of PI3K is Independent of Integrins $\alpha 5 \beta 1$

Binding in Dormant Cells

We have previously demonstrated that the PI3K pathway is activated in these dormant cells [3]. This activation is sustained for the 5 days assayed and its inhibition blocked survival of the dormant clones. We investigated whether the activation of the PI3K survival pathway was dependent on binding of integrins $\alpha 5 \beta 1$. Figure 7 is a western blot that demonstrates that inhibiting integrin $\alpha 5 \beta 1$ binding with blocking antibody or blocking peptide P1 had no effect on Akt phosphorylation. An inhibitor of PI3K, LY294002, was used as a positive control. These data suggest that PI3K activation by FGF-2 is mediated directly by FGF-2-mediated signaling, independent of signaling by integrin $\alpha 5 \beta 1$.

PI3K Activation is Necessary for Cortical Actin Redistribution in Dormant Cells

To determine if dual signaling by FGF-2 through PI3K as well as ligation of the upregulated integrin $\alpha 5 \beta 1$ is required for the cortical actin rearrangement in the dormant cells, we incubated the cells with the PI3K inhibitor LY294002. Figure $8 \mathrm{a}$ demonstrates that dormant cells incubated with LY294002 lost their spread appearance and their cortical actin rearrangement and developed stress fibers. Figure $8 \mathrm{~b}$ shows that the percentage of cells with cortical actin increased from $33.1+11.5 \%$ in growing cells to $74.2+7.7$ in the dormant cells $(p<0.01)$, an effect reversed by the PI3K inhibitor to $30.88+15.5 \%(p<0.01)$. These data suggest that dual signaling by FGF-2 directly through $\mathrm{PI} 3 \mathrm{~K}$ and through integrin $\alpha 5 \beta 1$ is necessary for cortical rearrangement in dormant cells.

Membrane Localization of GRAF and Inactivation of RhoA Require PI3K Activity

Since guanine exchange factors and GTP activating proteins have both been linked to PI3K activity, we investigated whether the inactivation of RhoA in dormant cells was dependent on activation of PI3K. Figure 9a demonstrates that both the loss of membrane localization of RhoA and the reciprocal membrane re-localization of GRAF in dormant clones are reversed by inhibition of PI3K with LY294002.

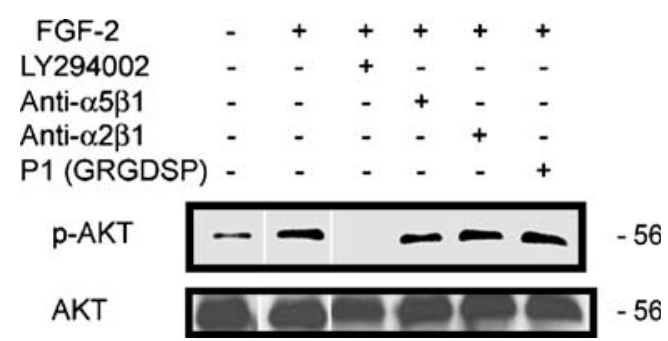

Fig. 7 Akt activation by FGF-2 in dormant cells is independent of integrin $\alpha 5 \beta 1$ ligation. Western blots of lysates from cells incubated on fibronectin with and without FGF-2 $10 \mathrm{ng} / \mathrm{ml}$ or blocking antibodies to integrin $\alpha 5 \beta 1$ or integrin $\alpha 2 \beta 12 \mu \mathrm{g} / \mathrm{ml}$, blocking peptide P1 to fibronectin $100 \mathrm{~nm}$, or PI3K inhibitor LY294002 $25 \mu \mathrm{M}$ on day 3, as described in Materials and Methods, were stained with antibody to phospho-Akt or total Akt 
Fig. 8 Cortical actin stabilization in dormant breast cancer cells is PI3K-dependent. a MCF-7 cells incubated with or without FGF-2 $10 \mathrm{ng} / \mathrm{ml}$ on fibronectin-coated cover slips at clonogenic density, with and without addition of LY294002 $25 \mu \mathrm{M}$ on day 3 were stained on day 6 with BODIPY-Phallacidin (green actin staining) and DAPI (blue nuclear staining) and photographed at $400 \times$ magnification. The figure demonstrates cortical actin distribution that appears in dormancy and is reversed by PI3K inhibition. The appearance of stress fibers and loss of the characteristic cell spreading is evident in dormant cells inhibited by LY294002. b Quantitative representation of manually counted cells with cortical actin on triplicate slides from a duplicate experiment demonstrating an increase in cortical actin with dormancy and reversal with PI3K inhibition. Error bars are + standard deviations. ${ }^{*} p<0.01$ (Student's t test)

\section{a}
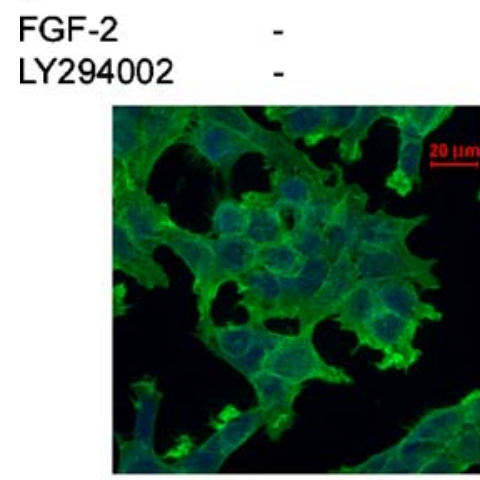
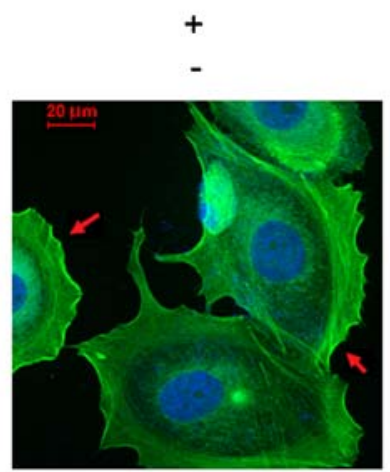

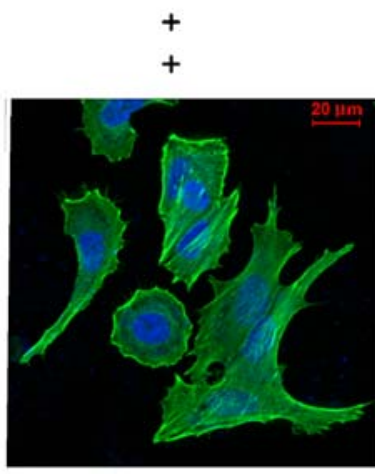

b

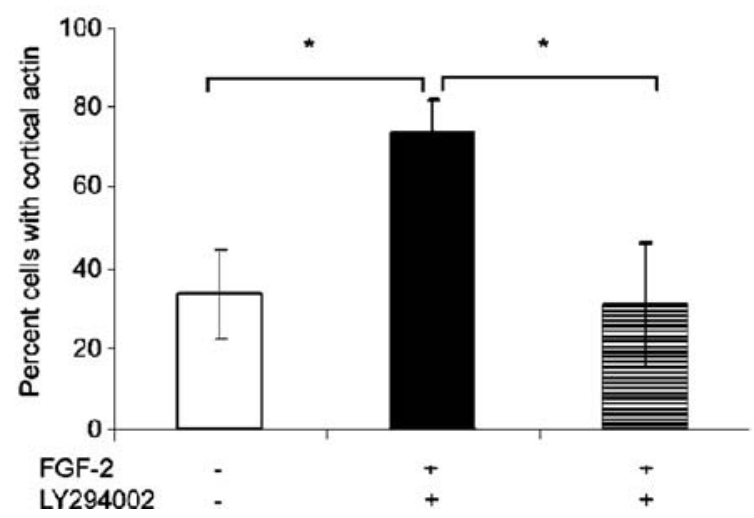

This was confirmed by membrane fractionation experiments for GRAF that demonstrated that the change in the GRAF m/ c ratio from 0.46 to 1.21 from growing to dormant cells was reversed to 0.23 by incubation of cells with the PI3K inhibitor (Fig. 9b). These experiments demonstrate that the activation of GRAF, inactivation of RhoA and the cortical redistribution of fibrillar actin in dormant cells require PI3K activation.

Figure 10 depicts a summary of the data presented demonstrating the factors that modulate the elements of dormancy assayed in this model. It indicates that FGF-2initiated signaling induces an upregulation of integrin $\alpha 5 \beta 1$ over a period of several days. Dual signaling by FGF-2 through PI3K and independent signaling through integrin $\alpha 5 \beta 1$ induce activation of FAK and membrane localization and activation of the RhoA GAP GRAF. This results in inactivation of RhoA and a permissive steady state for cortical rearrangement of F-actin. Follow up investigations into the transition to this steady state are ongoing.

\section{Discussion}

We have previously demonstrated that estrogen sensitive breast cancer cells, analogous to ones likely to remain dormant as microscopic metastases in the bone marrow microenvironment of patients, can enter a state of relative dormancy in an in vitro model [3]. The model encompasses some key components of the bone marrow niche, which include FGF-2 and fibronectin. Estrogen sensitive cells are induced by FGF-2 to go into G1 arrest through induction of cdk inhibitors [14], to re-express integrins lost with malignant progression [3] and to develop a distinct phenotype consisting of a large, spread out appearance, large cytoplasm to nucleus ratios [3] and to acquire resistance to chemotherapy with taxanes [26].

Here, we demonstrate that the spread appearance corresponds to cortically rearranged fibrillar actin and omnidirectionally activated FAK at the cell periphery. Circumferential actin bundle formation is another element of re-differentiation in these dormant cells. Cortical actin is observed exclusively in nontransformed mammary epithelial cells, disappears and is replaced by stress fibers during malignant transformation [33]. These effects are similar to ones we have previously demonstrated to occur with redifferentiation of a highly malignant breast cancer cell line, MDA-MB-231, upon enforced expression of FGF-2 [27], a growth factor whose expression stops during the process of mammary epithelial cell progression to malignancy [40].

The activation of FAK, however, appears to be counterintuitive to the re-differentiation process when first encountered. FAK activation is associated with integrinmediated adhesion and motility and is the mainstay of focal adhesion complexes initiating stress fibers. FAK 


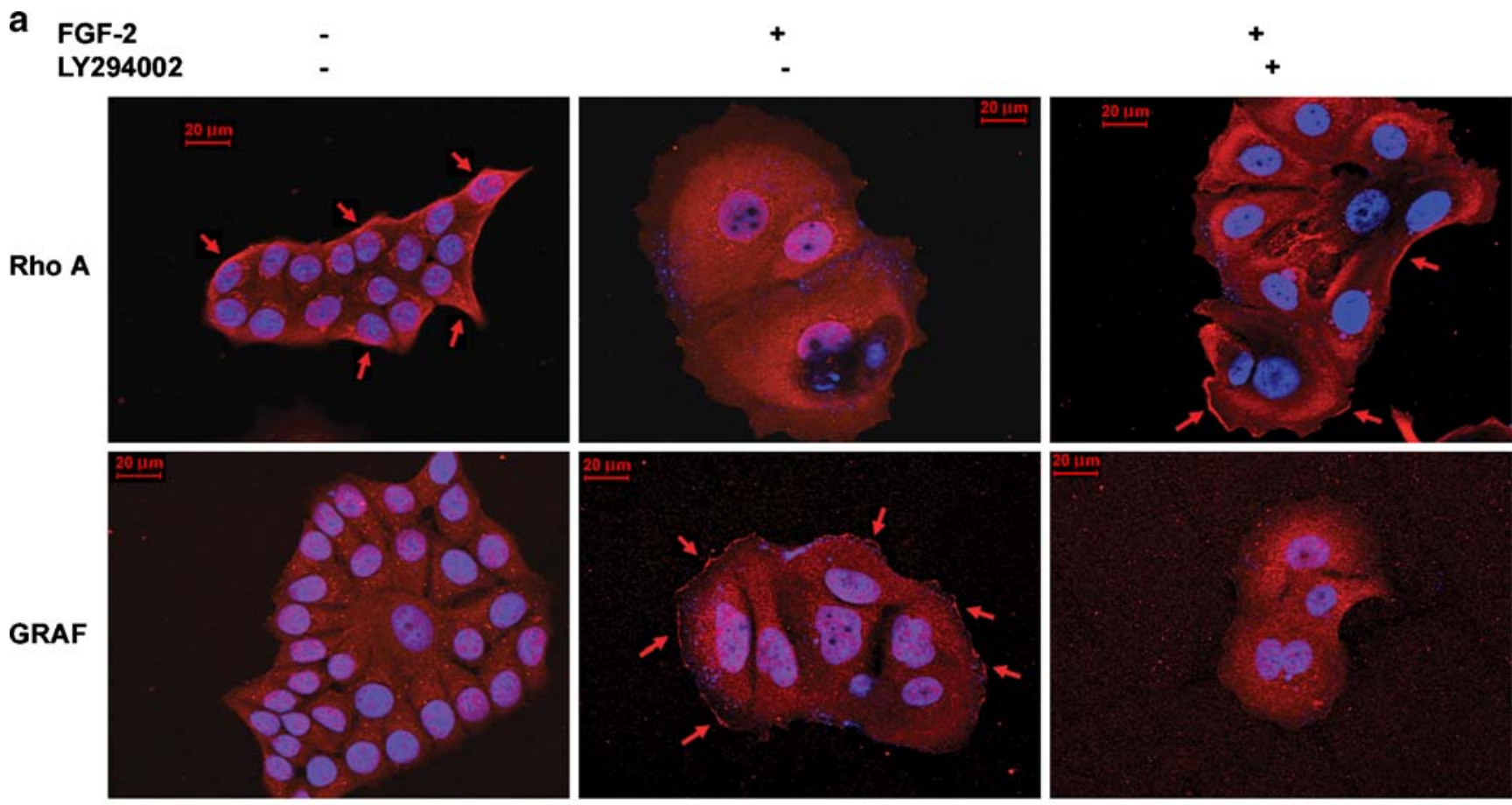

b

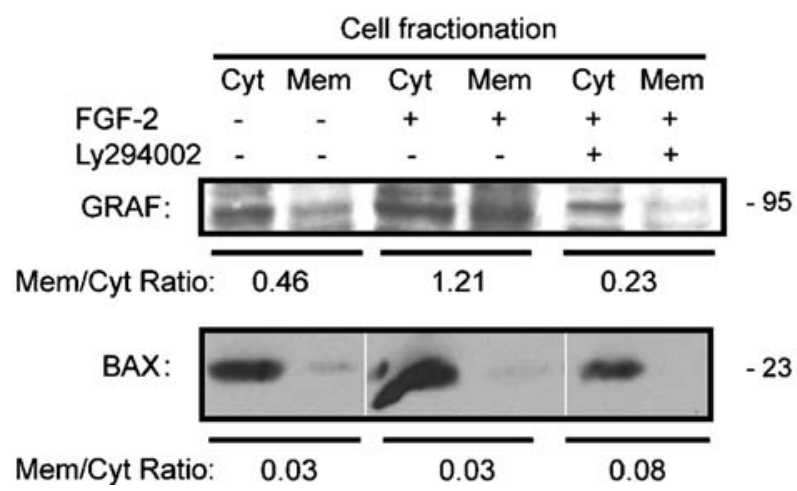

Fig. 9 Membrane localization of GRAF in dormant cells is PI3Kdependent. a GRAF membrane localization in dormant cells and the corresponding RhoA departure form its membrane localization was demonstrated on immunofluorescence-stained cells on fibronectincoated cover slips (red) and photography at $630 \mathrm{x}$ magnification. Addition of LY294002 $25 \mu \mathrm{M}$ on day 3 to the incubation medium resulted in abrogation of the membrane localization of GRAF and a corresponding membrane re-localization of RhoA (arrows). Growing cells exhibited membrane localization of RhoA (arrows) which

disappeared in dormant cells, while GRAF membrane localization appeared in dormant cells (arrows). Nuclear DAPI staining is shown in blue. b Membrane fractionation of growing and dormant cells with and without added LY294002 $25 \mu \mathrm{M}$ and western blotting of isolates with antibody to GRAF and BAX, used as a cytoplasm-localizing control, demonstrates that the membrane localization of GRAF in dormant cells is reversed by blocking of PI3K signaling. Bands were quantitated using a densitometer and ratios of membrane- to cytoplasm-localizing GRAF and BAX were calculated

levels are elevated and its activation plays a role in breast cancer progression [35-39]. However, our data showing that the activated FAK is complexed with GRAF in dormant breast cancer cells supports a role in a more differentiated state. GRAF is a protein with RhoA and dcdc42 GAP activity discovered in leukemic cells [41]. GRAF binds to the C-terminal domain of FAK in an SH3 domain-dependent manner [42] and blocks Rho-mediated stress fiber formation [43]. This can be regarded as contributing to partial cancer cell re-differentiation, since RhoA is the primary cause of stress fiber formation and increased motility of cancer cells, and trends to higher expression with tumor grade and nodal metastasis in breast cancer [29]. This report is the first account for a putative role for GRAF in the inactivation of RhoA in dormant breast cancer cells in this in vitro model.

The inactivation of RhoA appears to be at steady state and Rhotekin pulldown assays for RhoA GTP did not demonstrate downregulation at earlier times (data not shown). It is most likely that actin polymerization took place before the steady state of dormancy was achieved, and F-actin was stabilized in the cortical distribution after 


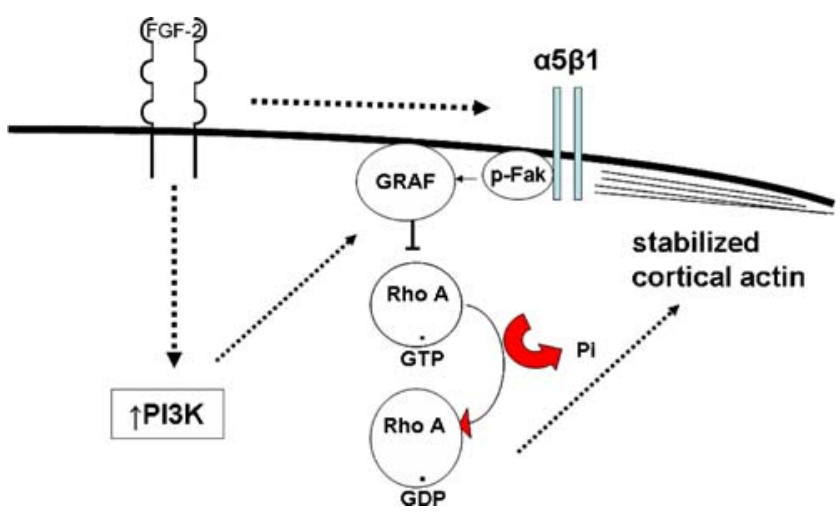

Fig. 10 Schema of dual FGFR and integrin $\alpha 5 \beta 1$ parallel steady state signaling in the dormancy model. The schema indicates FGF-2initiated upregulation of integrin $\alpha 5 \beta 1$ which reaches steady state after several days. Dual signaling through FGFR through PI3K and independently through integrin $\alpha 5 \beta 1$ induces activation of FAK and membrane localization and activation of the RhoA GAP GRAF. This results in inactivation of RhoA and a permissive steady state for cortical rearrangement of $\mathrm{F}$-actin

inactivation of RhoA. We assayed for activation of both Rac and cdc42 to determine the effects of dormancy on other members of the small GTPase family. The GTP loading of cdc42 was diminished, but Rac GTP loading was unaffected (data not shown). The effect is likely due to family member specificity of the GRAF family [42, 44, 45] due to a favorable interaction of the GRAF 231-residue BH domain, which harbors its GAP activity [46] with Glu-95 of Cdc42 and Glu-97 of RhoA, and is absent in the corresponding Ala-95 of Rac1 [44]. Rac and RhoA have a reciprocal relationship, and Rac activity remains unchecked with the inactivation of RhoA [47]. This is one likely explanation for the distinct appearance of lamellopodia on dormant cells (Figs. 1a, 3b, 4a, 5a, 6b, 8a, 9a). However, without the ability to form stress fibers, the characteristic motility due to Rac activation does not occur [48].

The role of PI3K in GRAF activation is also novel. We demonstrated that the survival of these dormant cells depends, in part, on activation of the PI3K pathway. The data presented here demonstrate that parallel signaling induced by exogenous FGF-2 through PI3K and by integrin $\alpha 5 \beta 1$ is necessary for activation of this GAP. The levels of GRAF were not affected in dormant cells as demonstrated by western blot (data not shown). However, its membrane localization depended on both exogenous FGF-2 through PI3K and binding of integrin $\alpha 5 \beta 1$. The mechanism is not understood and will be studied in follow up investigations. However, an association with FAK has been demonstrated. Whether this association is direct or through elements of the well recognized large complex is yet to be determined and will be investigated.

PIK3CA, the gene coding for the catalytic subunit of $\mathrm{PI} 3 \mathrm{~K}$, is mutated in $18-40 \%$ of breast cancers [49]. The mutations are in "hotspots" in exons 9, corresponding to the helical domain and exon 20, corresponding to the kinase domain in $85-100 \%$ of cases $[50,51]$. While the importance of the PI3K pathway in mammary tumorigenesis has been extensively investigated, opposing conclusions regarding mutations in the PIK3CA gene in primary breast tumors have been reached by different groups $[50,52]$. A potential explanation for the conflicting reports came to light more recently when a more focused analysis reported that mutations in exon 9 are associated with a significantly worse prognosis for disease-free and overall survival while mutations in exon 20 are associated with prolonged survival [51]. Also, while a mutation in Akt 1 has finally been identified in a number of malignancies, including breast cancer [53], the role of Akt activation in initiating malignant transformation is yet to be clarified [54]. With respect to breast cancer dormancy, the significance of frequent mutations in the PI3K pathway is not at all understood. It is possible that activating mutations may render cells resistant to therapy and permit survival of metastatic cells in the bone marrow niche. We have previously shown that the activated PI3K pathway is necessary for survival of this dormancy model [3] but induction of the dormant, non-proliferative state depends on FGF-2-initiated signals that activate a variety of pathways in addition to $\mathrm{PI} 3 \mathrm{~K}$.

In conclusion, we have shown that dormancy of estrogen sensitive breast cancer cells in a three component in vitro model encompasses a partial re-differentiation of breast cancer cells in close contact with elements of the microenvironement, which consist of inhibition of proliferation, re-expression of integrins lost with malignant transformation, cell spreading with omnidirectional FAK activation, activation of the RhoA GAP GRAF through exogenous FGF-2-mediated activation of PI3K and through integrin $\alpha 5 \beta 1$ ligation, with a resultant inactivation of RhoA and cortical actin rearrangement. Follow-up investigations will determine the mechanisms of achieving this steady state or dormancy and mechanisms for overcoming drug resistance in the dormant cells. Additional components will be added to the model, including a third dimension to validate the biological implications of our data prior to in vivo confirmation. In vivo effects of modulating RhoA activation in a murine metastasis model will confirm the functional role of RhoA inactivation in maintaining dormancy in micrometastases.

This model is one of several that have begun to generate data and hypotheses regarding this little understood but enormously significant biologic phenomenon. Our model fits with the concept of reversible growth/ proliferation arrest or quiescence governed by a genetic program which ensures the suppression of terminal differentiation [55]. The panel of genes comprising this state is activated regardless of the signal that initiates 
growth arrest. We have previously demonstrated that FGF2 initiates reversible growth arrest in MCF-7 and T-47D cells [14] and that this effect is mediated through TGF $\beta$ [56]. TGF $\beta$ and the BMP family are inhibitory to breast cancer cells that have not undergone epithelial mesenchymal transition [57] and can suppress micrometastases when administered in vivo [58].

A well-developed model of dormancy demonstrates a role for the urokinase receptor (u-PAR) activation in the exit from dormancy [59]. The model describes the upregulation of integrin $\alpha 5 \beta 1$, and the ability of the latter to propagate signals from fibronectin through the EGFreceptor and ERK to cause single quiescent cells to enter the cell cycle [59]. Similarly, a recent model of breast cancer dormancy demonstrated that the transition from quiescence to proliferation of breast cancer cells was dependent on fibronectin production and signaling through integrin $\beta 1$, leading to cytoskeletal reorganization with F-actin stress fiber formation [60]. These models are completely congruent with our hypothesis, despite first impressions. We have previously demonstrated that fibronectin increases the number of dormant MCF-7 and T-47D clones incubated with FGF-2, but nevertheless, the cells remain dormant [3]. The likely explanation is that activation of proliferative signaling by ligation of integrin $\alpha 5 \beta 1$ by fibronectin and by FGF-2 mediated activation of the ERK pathway and upregulation of cyclin D [14] are trumped by FGF-2-induced parallel cell cycle inhibition and partial rediferrentiation. FGF-2-initiated signaling results in upregulation of $\mathrm{p} 21^{\mathrm{WAF} 1 / \mathrm{Cip} 1}$ [14] and $\mathrm{p} 27^{\mathrm{KIP} 1}$ [56] and reexpression of integrins lost with de-differentiation [3], which collectively contribute to the dormant phenotype observed.

Acknowledgements Supported by DAMD17-03-1-0524 (RW) and the Ruth Estrin Goldberg Memorial for Cancer Research (RW)

Open Access This article is distributed under the terms of the Creative Commons Attribution Noncommercial License which permits any noncommercial use, distribution, and reproduction in any medium, provided the original author(s) and source are credited.

\section{References}

1. Braun S, Pantel K, Muller P et al (2000) Cytokeratin-positive cells in the bone marrow and survival of patients with stage I, II, or III breast cancer. N Engl J Med 342:525-533

2. Braun S, Kentenich C, Janni W et al (2000) Lack of an effect of adjuvant chemotherapy on the elimination of single dormant tumor cells in bone marrow of high risk breast cancer patients. $\mathrm{J}$ Clin Onc 18:80-86

3. Korah R, Boots M, Wieder R (2004) Integrin $\alpha 5 \beta 1$ promotes survival of breast cancer cells: an in vitro paradigm for breast cancer cell dormancy in the bone marrow. Can Res 64:4514-4522

4. Nguyen PL, Taghian AG, Katz MS et al (2008) Breast cancer subtype approximated by estrogen receptor, progesterone receptor, and HER-2 is associated with local and distant recurrence after breast-conserving therapy. J Clin Oncol 26:2373-2378

5. Haffty BG, Yang Q, Reiss M et al (2006) Locoregional relapse and distant metastasis in conservatively managed triple negative early-stage breast cancer. J Clin Oncol 24:5652-5657

6. Dent R, Trudeau M, Pritchard KI et al (2007) Triple-negative breast cancer: clinical features and patterns of recurrence. Clin Cancer Res 13(15 Pt 1):4429-4434

7. Cazzaniga M, Pronzato P, Leto di Priolo SL et al (2004) Patterns of relapse and modalities of treatment of breast cancer: the 'IRIS' Project, a multicenter observational study. Oncology 66:260-268

8. Nicolini A, Giardino R, Carpi A et al (2006) Metastatic breast cancer: an updating. Biomedicine \& Pharmacotherapy 60:548-556

9. Nilsson SK, Debatis ME, Dooner MS et al (1998) Immunofluorescence characterization of key extracellular matrix proteins in murine bone marrow in situ. J Histochem \& Cytochem 46:371-377

10. Van der Velde-Zimmermann D, Verdaasdonk MA, Rademakers LH et al (1997) Fibronectin distribution in human bone marrow stroma: matrix assembly and tumor cell adhesion via $\alpha 5 \beta 1$ integrin. Exp Cell Res 230:111-120

11. Balduino A, Hurtado SP, Frazao P et al (2005) Bone marrow subendosteal microenvironment harbours functionally distinct haemosupportive stromal cell populations. Cell \& Tissue Research 319:255-266

12. Psaila B, Kaplan RN, Port ER et al (2006) Priming the 'soil' for breast cancer metastasis: the pre-metastatic niche. Breast Disease 26:65-74

13. Sinowatz F, Schams D, Plath A et al (2000) Expression and localization of growth factors during mammary gland development. In: Mol JA, Clegy RA (eds) Biology of the Mammary Gland. Kluwer Acad, New York, pp 19-25

14. Wang H, Rubin M, Fenig E et al (1997) Basic FGF causes growth arrest in MCF-7 human breast cancer cells while inducing both mitogenic and inhibitory $\mathrm{G}_{1}$ events. Cancer Res 57:1750-1757

15. Korah R, Sysounthone V, Scheff E et al (2000) Intracellular FGF2 promotes differentiation in T47-D breast cancer cells. Biochem Biophys Res Comm 277:255-260

16. Korah R, Sysounthone V, Golowa Y et al (2000) Basic fibroblast growth factor confers a more differentiated phenotype in MDAMB-231 human breast cancer cells. Cancer Res 60:733-740

17. Wieder R, Fenig E, Wang H et al (1998) Overexpression of basic fibroblast growth factor in MCF-7 human breast cancer cells: lack of correlation between inhibition of cell growth and MAP kinase activation. J. Cellular Physiology 177:411-425

18. Brunner G, Nguyen H, Gabrilove J et al (1993) Basic fibroblast growth factor expression in human bone marrow and peripheral blood cells. Blood 81:631-638

19. Yoon SY, Li CY, Lloyd RV et al (2000) Bone marrow histochemical studies of fibrogenic cytokines and their receptors in myelodisplastic syndrome with myelofibrosis and related disorders. Int J Hematol 72:337-342

20. Brunner G, Gabrilove J, Rifkin DB et al (1991) Phospholipase C release of basic fibroblast growth factor from human bone marrow cultures as a biologically active complex with a phosphatidylinositol-anchored heparan sulfate proteoglycan. J Cell Biol 114:1275-1283

21. Gabrilove JL, White K, Rahman Z et al (1993) Stem cell factor and basic fibroblast growth factor are synergistic in augmenting commited myeloid progenitor cell growth. Blood 83:907-910

22. Brunner G, Metz CN, Nguyen H et al (1994) An endogenous glycosylphosphatidylinositol-specific phospholipase D releases basic fibroblast growth factor-heparan sulfate proteoglycan complexes from human bone marrow cultures. Blood 83:21152125

23. Howlett AR, Bailey N, Damsky C et al (1995) Cellular growth and survival are mediated by beta 1 integrins in normal human breast 
epithelium but not in breast carcinoma. J Cell Sci 108(Pt 5):19451957

24. Shaw LM (1999) Integrin function in breast carcinoma progression. J Mammary Gland Biol \& Neoplasia 4:367-376

25. Gui GP, Wells CA, Yeomans P et al (1996) Integrin expression in breast cancer cytology: a novel predictor of axillary metastasis. European J Surgical Oncol 22:254-258

26. Najmi S, Korah R, Chandra R et al (2005) Flavopiridol blocks integrin-mediated survival in dormant breast cancer cells. Clin Can Res 11:2038-2046

27. Korah R, Choi L, Barrios J et al (2004) Expression of FGF-2 alters focal adhesion dynamics in migration-restricted MDA-MB231 breast cancer cells. Breast Cancer Res Treat 88:17-28

28. Ellenbroek SI, Collard JG (2007) Rho GTPases: functions and association with cancer. Clinical \& Experimental Metastasis 24:657-672

29. Jiang WG, Watkins G, Lane J et al (2003) Prognostic value of rho GTPases and rho guanine nucleotide dissociation inhibitors in human breast cancers. Clinical Cancer Res 9:6432-6440

30. Maloof P, Wang Q, Wang H et al (1999) Overexpression of retrovirally transduced basic FGF in MCF-7 human breast cancer cells downregulates Bcl-2 and sensitizes cells to chemotherapyinduced apoptosis. Breast Cancer Res Treatment 56:153-167

31. Whitehead I, Kirk H, Tognon C et al (1995) Expression cloning of lfc, a novel oncogene with structural similarities to guanine nucleotide exchange factors and to the regulatory region of protein kinase C. J Biol Chem 270:18388-18395

32. Rodriguez PL, Sahay S, Olabisi OO et al (2007) ROCK Imediated activation of NF-kappaB by RhoB. Cellular Signalling 19:2361-2369

33. Zhong C, Kinch MS, Burridge K (1997) Rho-stimulated contractility contributes to the fibroblastic phenotype of Ras transformed epithelial cells. Mol Biol Cell 8:2329-2344

34. Mitra SK, Schlaepfer DD (2006) Integrin-regulated FAK-Src signaling in normal and cancer cells. Current Opinion in Cell Biology 18:516-23

35. Cance WG, Harris JE, Iacocca MV et al (2000) Immunohistochemical analyses of focal adhesion kinase expression in benign and malignant human breast and colon tissues: correlation with preinvasive and invasive phenotypes. Clin Cancer Res 6:2417-2423

36. Lark AL, Livasy CA, Dressler L et al (2005) High focal adhesion kinase expression in invasive breast carcinomas is associated with an aggressive phenotype. Modern Pathol 18:1289-1294

37. Lin HJ, Hsieh FC, Song H et al (2005) Elevated phosphorylation and activation of PDK-1/AKT pathway in human breast cancer. British J Cancer 93:1372-1381

38. van Nimwegen MJ, Verkoeijen S, van Buren L et al (2005) Requirement for focal adhesion kinase in the early phase of mammary adenocarcinoma lung metastasis formation. Cancer Res 65:4698-4706

39. Watermann DO, Gabriel B, Jager M et al (2005) Specific induction of pp125 focal adhesion kinase in human breast cancer. British J. Cancer 93:694-698

40. Korah R, Das K, Lindy ME et al (2007) Co-ordinate loss of FGF2 and laminin 5 expression during neoplastic progression of mammary duct epithelium. Human Pathology 38:154-160

41. Borkhardt A, Bojesen S, Haas OA et al (2000) The human GRAF gene is fused to MLL in a unique $\mathrm{t}(5 ; 11)(\mathrm{q} 31 ; \mathrm{q} 23)$ and both alleles are disrupted in three cases of myelodysplastic syndrome/ acute myeloid leukemia with a deletion 5q. Proc Natl Acad Sci USA 97:9168-9173
42. Hildebrand JD, Taylor JM, Parsons JT (1996) An SH3 domaincontaining GTPase-activating protein for Rho and Cdc42 associates with focal adhesion kinase. Molecular \& Cellular Biology 16:3169-3178

43. Taylor JM, Macklem MM, Parsons JT (1999) Cytoskeletal changes induced by GRAF, the GTPase Associated with Focal Adhesion Kinase, are mediated by Rho. J Cell Sci 112:231-242

44. Longenecker KL, Zhang B, Derewenda U et al (2000) Structure of the $\mathrm{BH}$ domain from Graf and its implications for Rho GTPase recognition. J Biol Chem 275:38605-38610

45. Shibata H, Oishi K, Yamagiwa A et al (2001) PKNbeta interacts with the SH3 domains of Graf and a novel Graf related protein, Graf2, which are GTPase activating proteins for Rho family. J Biochem 130:23-31

46. Sheffield PJ, Derewenda U, Taylor J et al (1999) Expression, purification and crystallization of a $\mathrm{BH}$ domain from the GTPase regulatory protein associated with focal adhesion kinase. Acta Crystallographica Section D-Biological Crystallography 55(Pt 1):356-359

47. Simpson KJ, Dugan AS, Mercurio AM (2004) Functional analysis of the contribution of RhoA and RhoC GTPases to invasive breast carcinoma. Cancer Res 64:8694-8701

48. Chan AY, Coniglio SJ, Chuang YY et al (2005) Roles of the Rac1 and Rac3 GTPases in human tumor cell invasion. Oncogene 24:7821-7829

49. Karakas B, Bachman KE, Park BH (2006) Mutation of the PIK3CA oncogene in human cancers. Br J Cancer 94:455459

50. Maruyama N, Miyoshi Y, Taguchi T et al (2007) Clinicopathologic analysis of breast cancers with PIK3CA mutations in Japanese women. Clin Cancer Res 13:408-414

51. Barbareschi M, Buttitta F, Felicioni L et al (2007) Different prognostic roles of mutations in the helical and kinase domains of the PIK3CA gene in breast carcinomas. Clin Cancer Res 13:6064 6069

52. Li SY, Rong M, Grieu F et al (2006) PIK3CA mutations in breast cancer are associated with poor outcome. Breast Cancer Res Treat 96:91-95

53. Carpten JD, Faber AL, Horn C et al (2007) A transforming mutation in the pleckstrin homology domain of AKT1 in cancer. Nature 448:439-444

54. Blanco-Aparicio C, Renner O, Leal JF et al (2007) PTEN, more than the AKT pathway. Carcinogenesis 28:1379-1386

55. Coller HA, Sang L, Roberts JM (2006) A new description of cellular quiescence. Plos Biology 4:e83

56. Fenig E, Kanfi Y, Wang Q et al (2001) Role of transforming growth factor beta in the growth inhibition of human breast cancer cells by basic fibroblast growth factor. Breast Cancer Res Treat 70:27-37

57. Buijs JT, Henriquez NV, van Overveld PG et al (2007) TGF-beta and BMP7 interactions in tumour progression and bone metastasis. Clinical \& Experimental Metastasis 24:609-617

58. Buijs JT, Henriquez NV, van der Horst G et al (2007) Bone morphogenetic protein 7 in the development and treatment of bone metastases from breast cancer. Cancer Res 67:8742-8751

59. Allgayer H, Aguirre-Ghiso JA (2008) The urokinase receptor (u-PAR)-a link between tumor cell dormancy and minimal residual disease in bone marrow? APMIS 116:602-614

60. Barkan D, Kleinman H, Simmons JL et al (2008) Inhibition of metastatic outgrowth from single dormant tumor cells by targeting the cytoskeleton.. Cancer Res 68:6241-6250 